\title{
Factors affecting the fruit and vegetable intake in Nepal and its association with history of self-reported major cardiovascular events
}

Sajama Nepali ${ }^{*}$ (D), Anupa Rijal ${ }^{2}$, Michael Hecht Olsen ${ }^{2}$, Craig S. McLachlan ${ }^{3}$, Per Kallestrup ${ }^{4}$ and Dinesh Neupane $e^{1,5}$

\begin{abstract}
Background: The World Health Organization recommends consumption of a minimum of $400 \mathrm{~g}$ of fruits and vegetables per day for prevention of cardiovascular disease. Low fruit and vegetable intake is associated with an increased risk of stroke by $11 \%$ and ischemic heart disease by $31 \%$. The present study aims to explore factors affecting the fruit and vegetable intake in Nepal and its association with history of self-reported major cardiovascular events (myocardial infarction and stroke).
\end{abstract}

Method: Data for this cross-sectional study were collected as part of the study "Community Based Management of Hypertension in Nepal" initiated in the Lekhnath Municipality in 2013. Demographic and nutrition information were collected using the WHO STEPwise approach to a surveillance tool. Descriptive statistics identified the frequency and percentage of fruit and vegetable intake. A Chi-square test examined the association between fruit and vegetable intake and history of self-reported cardiovascular events, socio-demographic and cardiovascular risk factors. Binary logistic regression analysis identified odds ratio with 95\% confidence intervals between fruit and vegetable intake and history of self-reported cardiovascular events.

Results: The mean and median intake of fruits and vegetables were $3.3 \pm 0.79$ and 3 servings respectively. Of the 2815 respondents, $2 \%$ (59) reported having a history of major cardiovascular events. The adjusted odds of having a history of major cardiovascular events was $2.22(95 \% \mathrm{Cl}, 1.06-4.66)$ for those who consumed $<3$ servings compared to those who consumed $\geq 3$ servings of fruits and vegetables a day.

Conclusion: The respondents who consumed $<3$ servings of fruits and vegetables a day had higher odds of a history of major cardiovascular events in comparison to those who consumed $\geq 3$ servings. This finding may carry a policy recommendation for those settings where the current recommendation of having $\geq 5$ servings of fruits and vegetables a day is not possible. Our findings also suggest that surviving a major cardiovascular event was not enough in itself to modify nutritional intake. As many Nepali consumes low amount of fruits and vegetables, appropriate measures should be taken to increase this consumption to prevent cardiovascular morbidity and mortality.

Keywords: Association, Fruit and vegetable, Nepal, Myocardial infarction, Self-reported, Stroke

\footnotetext{
* Correspondence: sajama.nepali@gmail.com

${ }^{1}$ Nepal Development Society, Chitwan, Nepal

Full list of author information is available at the end of the article
}

(c) The Author(s). 2020 Open Access This article is licensed under a Creative Commons Attribution 4.0 International License, which permits use, sharing, adaptation, distribution and reproduction in any medium or format, as long as you give appropriate credit to the original author(s) and the source, provide a link to the Creative Commons licence, and indicate if changes were made. The images or other third party material in this article are included in the article's Creative Commons licence, unless indicated otherwise in a credit line to the material. If material is not included in the article's Creative Commons licence and your intended use is not permitted by statutory regulation or exceeds the permitted use, you will need to obtain permission directly from the copyright holder. To view a copy of this licence, visit http://creativecommons.org/licenses/by/4.0/. The Creative Commons Public Domain Dedication waiver (http://creativecommons.org/publicdomain/zero/1.0/) applies to the data made available in this article, unless otherwise stated in a credit line to the data. 


\section{Background}

Fruits and vegetables are an essential part of a healthy and balanced diet $[1,2]$. Vitamins, minerals, fibers and phytochemicals in fruits and vegetables provide health advantages [1] and contribute to reduce risk factors for cardiovascular diseases [3]. The World Health Organization (WHO) recommends consumption of a minimum of $400 \mathrm{~g}$, corresponding to five servings of fruits and vegetables excluding potatoes and other tuberous root vegetables a day, to prevent cardiovascular diseases [4]. Low intake of fruits and vegetables is estimated to be responsible for $11 \%$ of strokes and $31 \%$ of ischemic heart disease cases [5]. WHO estimates that 2.7 million lives could be saved each year if fruits and vegetables are consumed adequately [5].

In line with WHO recommendations, studies have reported an inverse association between fruit and vegetable intake and cardiovascular diseases with an intake of 3 to 5 servings and more than 5 daily servings of fruits and vegetables significantly lowered the risk of cardiovascular diseases compared to consuming less than 3 servings a day [6]. Similarly, another study among female health professionals reported that a high intake of fruits and vegetables had a protective effect against cardiovascular diseases [7].

However, very few studies have documented fruit and vegetable intake in low-income countries like Nepal [8]. A nationwide study in Nepal conducted in 2013 reported that almost the entire study population (99\%) had an insufficient fruit and vegetable intake [9]. To the best of our knowledge, no studies have explored the association between fruit and vegetable intake and major cardiovascular events in Nepal. The aim of the present study was to explore the factors affecting fruit and vegetable intake in Nepal and its association with cardiovascular diseases assessed as self-reported history of major cardiovascular events (myocardial infarction or stroke).

\section{Methods}

Data of the current study were retrieved from the "Community Based Management of Hypertension in Nepal (COBIN)" study initiated in the former Lekhnath Municipality in 2013 [10], now merged into Pokhara Municipality after federalism in 2015. The detailed protocol and methodology of the project have been published elsewhere [10].

\section{Study area}

The study area was a semi-urban area of Pokhara Municipality (formerly known as Lekhnath Municipality) in the Kaski district of the Gandaki Province of western Nepal. Nepal has a diverse topography and has favorable climate for growing varieties of fruits and vegetables. A number of fruits and vegetables such as apple, peach, pear, plum, walnut, orange, mango, lichi, banana, pineapple, papaya, green leafy vegetables, radish, potato etc. are grown in Nepal [11].

\section{Study population}

The eligibility criteria were people aged between 25 and 65 years and listed on the voter list of 2007 in Pokhara Municipality in the Kaski district. People with severe illness such as people whose participation in this study would hamper their health condition and pregnant women were excluded. All participants in the study provided written informed consent before the enrolment.

\section{Study design and tools}

This cross-sectional study conducted in 2015 followed the WHO STEPwise approach to surveillance (STEPS) tool [12]. The tool has been validated and used by Nepal Health Research Council [9]. The tool provides information on physical measurements (height, weight), sociodemographics (age, sex, ethnicity, family size, occupation, income, education, etc.), lifestyle factors (salt consumption, smoking, alcohol, physical activity, etc.), and blood pressure (BP).

\section{Sample size and sampling procedure}

This is a further analysis of COBIN study. The sample size for this study was calculated based on the prevalence of hypertension in Nepal. The description has been discussed in detail elsewhere $[10,13]$. In brief, the random sample of participants were selected using voter list of the study municipality. Assuming $25 \%$ prevalence of hypertension, 95\% confidence intervals (CI) and a 5\% margin of error and eight strata based on age and sex group, 2882 participants were approached for data collection. While $2 \%$ of the sampled population did not give consent and/or were not available during the household visits, 2815 participants were included in this study, of which 1843 were female and 972 were male who provided complete information on history of self-reported major cardiovascular events and fruit and vegetable intake.

\section{Variables and definition of variables Socio-demographic characteristics}

The socio-demographic variables included in this study were age, ethnicity, sex and educational level. Age was measured in years and classified into four groups (2434, 35-44, 45-54 and 55-64 years). Ethnicity was subgrouped into three categories such as upper caste (advantaged ethnic group), janajati (relatively disadvantaged ethnic group) and others in accordance with the coding of the Government of Nepal [14]. Educational level was classified into three categories; primary school, secondary and high school, and college or university. 


\section{Major cardiovascular events}

For self-reported history of myocardial infarction and stroke, respondents were asked a prompt question in Nepali, "Have you ever had a stroke or heart attack?" If the respondent was not sure about their answer, they showed medical records from hospital and/or the bristle pack of medicine used for myocardial infarction and stroke.

\section{Fruit and vegetable intake}

Data collection on number of servings was done as a part of the WHO STEPS tool. "One cup of raw, leafy green vegetables, half a cup of other cooked or raw vegetables or half a cup of vegetable juice was regarded as one serving of vegetable. One medium-size piece of fruit, half a cup of raw, cooked or canned fruit, or half a cup of juice from a fruit (not artificially flavored) was considered as one serving of fruit [12]." A show card illustrated typical examples of local fruits and vegetables and participants were asked about the number of servings of fruits and vegetables. Each show card illustrated the size of the servings. Based on the show card, participants self-reported their number of daily servings. When the number of fruit and vegetable intake a day was disaggregated into $<5$ and $\geq 5$ servings, we found that $10.2 \%$ of respondents consumed $\geq 5$ servings a day and $89.8 \%$ consumed $<5$ servings of fruits and vegetables a day. Intake of fruit and vegetable was classified as $<3$ and $\geq 3$ servings based on the median value ( 3 servings a day) or mean values of 3.3 servings a day. A former prospective cohort study conducted across 18 countries have also classified fruit and vegetable serving into 3-4 servings and reported that even moderate consumption of fruits and vegetables (equivalent to 3-4 servings a day) resulted in significant reduction of all-cause mortality and lower incidence of cardiovascular diseases [15].

\section{Major risk factors of cardiovascular disease}

Body mass index (BMI) was calculated by dividing weight (in $\mathrm{kg}$ ) by square of height (in meters), classified as underweight $\left(<18.5 \mathrm{~kg} / \mathrm{m}^{2}\right)$, normal $\left(18.5-24.9 \mathrm{~kg} / \mathrm{m}^{2}\right)$ and overweight/obese $\left(\geq 25 \mathrm{~kg} / \mathrm{m}^{2}\right)$ [16]. In terms of physical activity, $<600$ Metabolic Equivalent of Task (MET) minutes/week was considered low, 600-3000 MET minutes/week was considered medium and $>3000$ MET minutes/week was considered high [12]. Harmful intake of alcohol was classified yes if men were drinking 15 or more standard drinks a week and if women were drinking 8 or more standard drinks a week [17]. If the systolic BP was $140 \mathrm{mmHg}$ or higher, if the diastolic BP was $90 \mathrm{mmHg}$ or higher or if using antihypertensive medication, then the respondent was considered to have hypertension [18]. Diabetes Mellitus was categorized as "yes" or "no", based on information provided by health professionals to establish if respondents had been diagnosed with diabetes mellitus within the last 12 months. Respondents were considered current smokers if reporting to currently smoking cigarettes.

\section{Statistical analysis}

Data analysis was performed using the statistical software R version 3.6.3 [19]. Descriptive statistics were carried out to identify the frequency and percentage of respondents according to fruit and vegetable intake. The Chi-square test was used to examine the association between fruit and vegetable intake and history of selfreported cardiovascular events, socio-demographic and cardiovascular risk factors. A $p$-value below 0.05 was considered statistically significant.

Binary logistic regression analysis was used to compute the odds ratio with $95 \%$ CI to find out the factors affecting fruit and vegetable intake where fruit and vegetable intake was regarded as outcome variable and sociodemographic (age, sex, ethnicity, education), cardiovascular risk (diabetes mellitus, currently smoking, hypertension, BMI, harmful alcohol consumption, physical activity) factors and history of self-reported cardiovascular events were independent variables. Both crude odds ratio (COR) and adjusted odds ratio (AOR) were reported. No variables were controlled in the crude model and all the independent variables such as sociodemographic (age, sex, education, ethnicity), cardiovascular risk factors (diabetes mellitus, currently smoking, hypertension, BMI, harmful alcohol consumption, physical activity) and history of self-reported cardiovascular events were controlled in the adjusted model (Table 3). Similarly, another binary logistic regression analysis was performed between history of self-reported major cardiovascular events and fruit and vegetable intake to compute the odds of having a history of major cardiovascular events for respondents who consumed $<3$ servings of fruits and vegetables in a day compared to those who consumed $\geq 3$ servings of fruits and vegetables in a day. The history of self-reported major cardiovascular events was regarded as outcome variable, fruit and vegetable intake, socio-demographic and cardiovascular risk factors were independent variables. No variables were controlled in the crude model and all the independent variables such as socio-demographic (age, sex, education, ethnicity), cardiovascular risk factors (diabetes mellitus, currently smoking, hypertension, BMI, harmful alcohol consumption, physical activity) and fruit and vegetable intake were controlled in the adjusted model (Table 4).

Data on age, BMI and physical activity were kept as continuous variables in the logistic regression. The likelihood ratio test was performed to compare the two models, i.e. one with the continuous variable and another with the same categorical variable. The $p$-value 
was more than 0.05 for all the three variables for likelihood ratio test and the null hypothesis was accepted. The model with continuous variable best fits the data and therefore, this model was chosen. No interaction was found between independent variables and fruit and vegetable intake.

\section{Ethics}

The Nepal Health Research council approved the protocol for the original study (reference number 1065). All study participants were informed about study objectives, procedures and their role in the study. Written informed consent was obtained from all participants before data collection.

\section{Results}

Table 1 shows the number of servings of fruits and vegetables a day as well as number of days of eating fruits and vegetables in a typical week. Half (49.3\%) of the respondents consumed one serving of fruit on average and 93.3\% consumed two servings of vegetables on average per day. The mean and median intake of fruits and vegetables were $3.3 \pm 0.79$ and 3 servings respectively.

Table 2 shows the distribution of respondents according to socio-demographic characteristics, self-reported history of major cardiovascular events and cardiovascular risk factors by number of fruit and vegetable servings a day. Among respondents who consumed $<3$ servings of fruits and vegetables a day, $3.4 \%$ of respondents reported having a history of major cardiovascular events and $96.6 \%$ reported not having a history of major cardiovascular events. Similarly, among those who consumed $\geq 3$ servings of fruits and vegetables a day, $1.9 \%$ of respondent reported having a history of major cardiovascular events and $98.1 \%$ reported not having a history of major cardiovascular events. Lastly, prevalence of selfreported history of major cardiovascular events was $2 \%$.

Table 3 presents the crude and adjusted odds ratios from the logistic regression analysis for finding out factors affecting the fruit and vegetable intake. Respondents with a secondary-level education had an AOR of 0.55 (95\% CI: 0.31-0.97) and those belonging to upper caste ethnicity had an AOR of 0.68 (95\% CI: $0.50-0.99)$ of consuming $<3$ servings of fruits and vegetables a day compared to those who consumed $\geq 3$ servings of fruits and vegetables a day. The respondents having a history of cardiovascular events (AOR 2.33; 95\%CI: 1.12-4.83) and currently smoking (AOR 1.39; 95\%CI: 1.01-1.91) had higher odds of consuming $<3$ servings of fruits and vegetables a day compared to those not having history of cardiovascular events and non-smokers respectively. Moreover, with every $1 \mathrm{~kg} / \mathrm{m}^{2}$ increase in BMI, the odds of consuming $<3$ servings of fruit and vegetable was
Table 1 Fruit and vegetable intake among persons aged 25-65 years respondents from Pokhara Municipality, Nepal, 2015

\begin{tabular}{cc}
\hline Fruit and vegetables intake & Frequency \%(N) \\
\hline Number of servings of fruit consumed on average per day $(N=2578)$ \\
1 & $49.3(1388)$ \\
2 & $41.2(1159)$ \\
3 & $0.8(22)$ \\
4 & $0.1(2)$ \\
5 & $0.0(0)$ \\
$\geq 6$ & $0.2(7)$
\end{tabular}

Number of days fruit was consumed in a typical week $(N=2795)$

$\begin{array}{ll}0 & 7.6(214) \\ 1 & 18.2(511) \\ 2 & 22.7(640) \\ 3 & 19.9(561) \\ 4 & 10.2(288) \\ 5 & 5.5(156) \\ \geq 6 & 15.1(425)\end{array}$

Number of vegetable servings consumed on average per day $(N=2809)$

$\begin{array}{ll}1 & 5.6(158) \\ 2 & 93.3(2625) \\ 3 & 0.8(23) \\ 5 & 0.0(1) \\ \geq 6 & 0.1(2)\end{array}$

Number of days vegetables were consumed in a typical week $(N=2814)$

$\begin{array}{ll}0 & 0.2(5) \\ 1 & 0.5(15) \\ 2 & 1.6(44) \\ 3 & 3.4(96) \\ 4 & 7.9(223) \\ 5 & 13.0(365) \\ \geq 6 & 73.4(2066)\end{array}$

0.95 (95\% CI: $0.92-0.98)$ times than that of consuming $\geq 3$ servings of fruits and vegetables a day.

Table 4 shows crude and adjusted odds ratios from logistic regression analysis for self-reported history of major cardiovascular events by fruit and vegetable intake, socio-demographic characteristics and risk factors related to cardiovascular diseases. The odds of having a history of major cardiovascular events was $1.82(95 \% \mathrm{CI}$ : 0.96-3.47) for respondents who consumed $<3$ servings of fruits and vegetables in a day compared to those who consumed $\geq 3$ servings of fruits and vegetables in a day without adjusting for socio-demographic and cardiovascular risk factors. When adjusting for sociodemographic and cardiovascular risk factors, the odds ratio increased to 2.22 (95\%CI: 1.06-4.66). A significant association was also noted between hypertension and 
Table 2 Fruit and vegetable intake by self-reported history of major cardiovascular events, socio-demographic characteristics and cardiovascular risk factors among persons aged 25-65 years respondents from Pokhara Municipality, Nepal, 2015

\begin{tabular}{|c|c|c|c|c|}
\hline \multirow[t]{2}{*}{ Characteristics } & \multicolumn{3}{|c|}{ Number of servings a day \% (N) } & \multirow[t]{2}{*}{$p$-value } \\
\hline & $<3$ servings & $\geq 3$ servings & Total & \\
\hline \multicolumn{4}{|l|}{ Age in years $(N=2656)$} & $0.001^{*}$ \\
\hline $24-34$ & $16.7(52)$ & $20.4(479)$ & 531 & \\
\hline $35-44$ & $25.4(79)$ & $30.6(717)$ & 796 & \\
\hline $45-54$ & $29.6(92)$ & $30.1(707)$ & 799 & \\
\hline $55-64$ & $28.3(88)$ & $18.8(442)$ & 530 & \\
\hline \multicolumn{4}{|l|}{ Ethnicity $(N=2815)$} & $<0.001^{*}$ \\
\hline Janajati & $33.0(116)$ & $32.8(808)$ & 924 & \\
\hline Others & $30.2(106)$ & $12.6(311)$ & 417 & \\
\hline Upper caste & $36.8(129)$ & $54.6(1345)$ & 1474 & \\
\hline \multicolumn{4}{|l|}{$\operatorname{Sex}(N=2815)$} & 0.981 \\
\hline Female & $65.5(230)$ & $65.5(1613)$ & 1843 & \\
\hline Male & $34.5(121)$ & $34.5(851)$ & 972 & \\
\hline \multicolumn{4}{|l|}{ Educational level $(N=2815)$} & $<0.001^{*}$ \\
\hline Up to primary & $68.4(240)$ & $49.8(1226)$ & 1466 & \\
\hline Secondary and high school & $26.8(94)$ & $43.7(1076)$ & 1170 & \\
\hline College or university & $4.8(17)$ & $6.6(162)$ & 179 & \\
\hline \multicolumn{4}{|c|}{ Harmful alcohol consumption $(N=2815)$} & $<0.001^{*}$ \\
\hline Yes & $43.9(154)$ & $34.4(847)$ & 1001 & \\
\hline No & $56.1(197)$ & $65.6(1617)$ & 1814 & \\
\hline \multicolumn{4}{|l|}{ Current smoking $(N=2815)$} & $<0.001^{*}$ \\
\hline Yes & $29.9(105)$ & $15.1(372)$ & 477 & \\
\hline No & $70.1(246)$ & $84.9(2092)$ & 2338 & \\
\hline \multicolumn{4}{|c|}{ History of major cardiovascular events $(N=2815)$} & 0.064 \\
\hline Yes & $3.4(12)$ & $1.9(47)$ & 59 & \\
\hline No & $96.6(339)$ & $98.1(2417)$ & 2756 & \\
\hline \multicolumn{4}{|l|}{ Hypertension $(N=2815)$} & 0.949 \\
\hline Yes & $29.9(105)$ & $29.7(733)$ & 838 & \\
\hline No & $70.1(246)$ & $70.3(1731)$ & 1977 & \\
\hline \multicolumn{4}{|l|}{ Diabetes Mellitus $(N=2815)$} & 0.839 \\
\hline Yes & $4.0(14)$ & $4.2(104)$ & 118 & \\
\hline No & $96.0(337)$ & $95.8(2360)$ & 2697 & \\
\hline \multicolumn{4}{|l|}{ Physical activity $(N=2815$ ) } & 0.453 \\
\hline Low & $1.1(4)$ & $0.6(14)$ & 18 & \\
\hline Moderate & $6.0(21)$ & $6.1(150)$ & 171 & \\
\hline High & $92.9(326)$ & $93.3(2300)$ & 2626 & \\
\hline \multicolumn{4}{|l|}{ BMI $(N=2815)$} & $<0.001^{*}$ \\
\hline Underweight & $12.5(44)$ & $5.9(145)$ & 189 & \\
\hline Normal & $52.1(183)$ & $43.9(1082)$ & 1265 & \\
\hline Overweight/obese & $35.3(124)$ & $50.2(1237)$ & 1361 & \\
\hline
\end{tabular}

BMI refers to body mass index. $\$ p$-value was reported from the Chi-square test performed between fruit and vegetable intake and history of self-reported cardiovascular events, socio-demographic and cardiovascular risk factors. * refers to statistically significant at $p$ value $<0.05$ 
Table 3 Crude and adjusted odds ratio from logistic regression analysis for identifying factors affecting the fruit and vegetable intake (reference $=\geq 3$ servings) among persons aged 25-65 years respondents from Pokhara Municipality, Nepal, 2015

\begin{tabular}{|c|c|c|c|c|c|c|}
\hline \multirow[t]{2}{*}{ Characteristics } & \multirow{2}{*}{$\begin{array}{l}\text { COR }^{a} \\
(< \\
\text { 3servings) }\end{array}$} & \multicolumn{2}{|l|}{$95 \% \mathrm{Cl}$} & \multirow{2}{*}{$\begin{array}{l}\text { AOR }^{b} \\
(< \\
\text { 3servings) }\end{array}$} & \multicolumn{2}{|l|}{$95 \% \mathrm{Cl}$} \\
\hline & & Lower Bound & Upper Bound & & Lower Bound & Upper Bound \\
\hline Age (in years) $(N=2656)$ & 1.02 & 1.01 & 1.03 & 1.01 & 0.99 & 1.03 \\
\hline \multicolumn{7}{|l|}{$\operatorname{Sex}(N=2815)$} \\
\hline Male & 1.00 & 0.79 & 1.26 & 0.92 & 0.66 & 1.27 \\
\hline Female & Ref & & & & & \\
\hline \multicolumn{7}{|l|}{ Educational level $(N=2815)$} \\
\hline Up to primary & 1.87 & 1.11 & 3.13 & 0.89 & 0.48 & 1.64 \\
\hline Secondary and high school & 0.83 & 0.48 & 1.43 & 0.55 & 0.31 & 0.97 \\
\hline College/ university & Ref & & & & & \\
\hline \multicolumn{7}{|l|}{ Ethnicity $(N=2815)$} \\
\hline Upper caste & 0.67 & 0.51 & 0.87 & 0.68 & 0.50 & 0.99 \\
\hline Others & 2.37 & 1.76 & 3.19 & 1.62 & 1.15 & 2.27 \\
\hline Janajati & Ref & & & & & \\
\hline \multicolumn{7}{|c|}{ History of major cardiovascular events $(N=2815)$} \\
\hline Yes & 1.82 & 0.96 & 3.47 & 2.33 & 1.12 & 4.83 \\
\hline No & Ref & & & & & \\
\hline \multicolumn{7}{|l|}{ Diabetes Mellitus $(N=\mathbf{2 8 1 5})$} \\
\hline Yes & 0.94 & 0.53 & 1.67 & 0.81 & 0.41 & 1.61 \\
\hline No & Ref & & & & & \\
\hline \multicolumn{7}{|l|}{ Hypertension $(N=2815)$} \\
\hline Yes & 1.01 & 0.79 & 1.29 & 1.00 & 0.75 & 1.34 \\
\hline No & Ref & & & & & \\
\hline \multicolumn{7}{|l|}{ Current smoking $(N=2815)$} \\
\hline Yes & 2.40 & 1.86 & 3.09 & 1.39 & 1.01 & 1.91 \\
\hline No & Ref & & & & & \\
\hline \multicolumn{7}{|c|}{ Harmful alcohol consumption $(N=2815)$} \\
\hline Yes & 1.50 & 1.19 & 1.88 & 1.09 & 0.80 & 1.49 \\
\hline No & Ref & & & & & \\
\hline $\begin{array}{l}\text { Physical activity } \\
\text { (MET/Week) } \\
(N=2815)\end{array}$ & 1.00 & 1.00 & 1.00 & 1.00 & 1.00 & 1.00 \\
\hline $\begin{array}{l}\text { BMI }(\mathrm{Kg} / \mathrm{m} 2) \\
(N=2815)\end{array}$ & 0.91 & 0.89 & 0.94 & 0.95 & 0.92 & 0.98 \\
\hline
\end{tabular}

Note: Age, physical activity and BMI are included as continuous variables in the model. COR refers to crude odds ratio, AOR refers to adjusted odds ratio, $\mathrm{Cl}$ refers to confidence intervals, MET refers to metabolic equivalent of task, BMI refers to body mass index and kg refers to kilogram. Fruit and vegetable intake was the outcome variable and socio-demographic (age, sex, education, ethnicity), cardiovascular risk factors (diabetes mellitus, currently smoking, hypertension, BMI, harmful alcohol consumption, physical activity) and history of self-reported cardiovascular events were independent variables. ${ }^{\mathrm{a}} \mathrm{No}$ adjustment done in the COR model. ${ }^{b}$ All the independent variables such as socio-demographic (age, sex, education, ethnicity), cardiovascular risk factors (diabetes mellitus, currently smoking, hypertension, BMI, harmful alcohol consumption, physical activity) and history of self-reported cardiovascular events were controlled in the AOR model

self-reported history of major cardiovascular events (AOR 9.17; 95\%CI: 4.44-18.94).

\section{Discussion}

The present study suggested an inverse association between intake of fruits and vegetables and self-reported history of myocardial infarction or stroke. The respondents consuming $<3$ servings of fruits and vegetables a day had a 2.22 (95\%CI: 1.06-4.66) adjusted odds of having a history of myocardial infarction or stroke. Our results support previous studies describing an inverse association between fruit and vegetable consumption and ischemic stroke [20,21]. Higher intake of fruits and vegetables was associated with lower risk of stroke in both studies [20, 21]. Interestingly, a prospective cohort study conducted across 18 countries reported that even 
Table 4 Crude and adjusted odds ratio from logistic regression of self-reported history of major cardiovascular events (reference = no cardiovascular events) by fruit and vegetable intake, socio-demographic characteristics and cardiovascular risk factors among persons aged 25-65 years respondents from Pokhara Municipality, Nepal, 2015

\begin{tabular}{|c|c|c|c|c|c|c|}
\hline \multirow[t]{2}{*}{ Characteristics } & \multirow{2}{*}{$\begin{array}{l}\text { COR }^{a} \\
\text { (Having } \\
\text { cardiovascular } \\
\text { events) }\end{array}$} & \multicolumn{2}{|l|}{$95 \% \mathrm{Cl}$} & \multirow{2}{*}{$\begin{array}{l}\text { AOR }^{b} \\
\text { (Having } \\
\text { cardiovascular } \\
\text { events) }\end{array}$} & \multicolumn{2}{|l|}{$95 \% \mathrm{Cl}$} \\
\hline & & Lower Bound & Upper Bound & & Lower Bound & Upper Bo \\
\hline
\end{tabular}

\section{No. of servings a day $(N=2815)$}

$<3$ servings
$\geq 3$ servings
Age (in years)

82

Ref

$(N=2656)$

$\operatorname{Sex}(N=2815)$

$\begin{array}{ll}\text { Male } & 1.22 \\ \text { Female } & \text { Ref }\end{array}$

Educational level $(N=2815)$

Up to primary
Secondary and high school
College/ university

\section{Ethnicity $(N=2815)$}

$\begin{array}{ll}\text { Upper caste } & 1.09 \\ \text { Others } & 0.81 \\ \text { Janajati } & \text { Ref }\end{array}$

\section{Diabetes Mellitus $(N=\mathbf{2 8 1 5})$}

$\begin{array}{ll}\text { Yes } & 2.67 \\ \text { No } & \text { Ref }\end{array}$

Hypertension $(N=2815)$

$\begin{array}{ll}\text { Yes } & 8.78 \\ \text { No } & \text { R }\end{array}$

\section{Current smoking $(N=2815)$}

$\begin{array}{ll}\text { Yes } & 1.26 \\ \text { No } & \text { Ref }\end{array}$

Harmful alcohol consumption $(N=2815)$

Yes

Physical activity
(MET/Week)
$(N=2815)$

$\begin{array}{lccccc}1.00 & 0.58 & 1.72 & 0.90 & 0.44 & 1.85 \\ \text { Ref } & 1.00 & 1.00 & 1.00 & 1.00 & 1.00 \\ 1.00 & 0.96 & 1.07 & 0.97 & 0.90 & 1.04 \\ 1.01 & 0.96\end{array}$

Note: Age, physical activity and BMI are included as continuous variables in the model. COR refers to crude odds ratio, AOR refers to adjusted odds ratio, $\mathrm{Cl}$ refers to confidence intervals, MET refers to metabolic equivalent of task, BMI refers to body mass index and kg refers to kilogram. History of self-reported cardiovascular events was the outcome variable, fruit and vegetable intake, socio-demographic (age, sex, education, ethnicity) and cardiovascular risk factors (diabetes mellitus, currently smoking, hypertension, BMI, harmful alcohol consumption, physical activity) were independent variable. ${ }^{a}$ No adjustment done in the COR model. ${ }^{b}$ All the independent variables such as socio-demographic (age, sex, education, ethnicity), cardiovascular risk factors (diabetes mellitus, currently smoking, hypertension, $\mathrm{BMI}$, harmful alcohol consumption, physical activity) and fruit and vegetable intake were controlled in the AOR model

moderate consumption of fruits and vegetables (equivalent to 3-4 servings a day) resulted in significant reduction of all-cause mortality and lower incidence of cardiovascular diseases [15].

The current study also demonstrated a significant association between hypertension and self-reported history of cardiovascular events. This is consistent with the results of a former study [22] showing that hypertension was an important risk factor of cardiovascular diseases.

Despite WHO recommendations of consuming $\geq 5$ servings of fruits and vegetables a day, the mean daily consumption of fruits and vegetables is inadequate 
especially in low- and middle-income countries like Nepal [23]. WHO has previously reported an average of 3.17 servings (2.99-3.35) per day in low- and middleincome countries [23]. On the other hand, we reported a slightly higher consumption in our study with an average of 3.3 servings per day.

We also found that the intake of fruits and vegetables varied among different socio-demographic variables. Respondents belonging to upper caste ethnicity were less likely to consume $<3$ servings of fruits and vegetables a day (AOR 0.68; 95\% CI: 0.50-0.99) compared to janajati. Similar to this result, a study conducted in India reported that the overall food consumption pattern was lower among people belonging to the lower caste group [24]. Upper caste people are moderately better educated [25] and wealthier than those belonging to other ethnicities [26]. Educational level was significantly associated with fruit and vegetable intake $(p<0.001)$. Respondents who had a secondary-level education were less likely to consume $<3$ servings of fruits and vegetables with an AOR of 0.55 (95\% CI: 0.31-0.97) than those who had attended college or university. This corroborates results of a South Asian study reporting that less educated people were less likely to consume adequate amounts of fruits and vegetables [27]. Thus, the policies and interventions targeted to increase consumption of fruits and vegetables should be designed as per the sociodemographic gradient of Nepal. Another study from same study area reported that individual lifestyle counselling alone would not help to consume more fruit and vegetable intake among the participants [28]. Thus, further research encompassing policies, market and economics are also needed to develop further plan and policies, which can be translated in the real scenario.

The prevalence of self-reported history of myocardial infarction and stroke was $2 \%$ in this study. This result is comparable to the result of a national survey done in Nepal in 2019 stating that $1.1 \%$ of adults aged 15-69 years reported ever having experienced a heart attack, angina or stroke [29]. Nepal has committed to a $25 \%$ relative reduction in premature death from noncommunicable diseases by 2025 [30]. However, Nepal is far behind translating guidelines to practice, specifically focusing dietary behaviors and practices. The National Nutrition Policy Strategy of 2004 recommends consuming a variety of fruits and vegetables [31]. The Multisectoral Action Plan for the Prevention and Control of Non-communicable diseases (2014-2020) encourages consumption of fruits and vegetables and discourages consumption of unhealthy foods [30] to prevent cardiovascular diseases; however, no specific guidelines are available.

\section{Strengths and limitations}

This is the first study from Nepal reporting the association between current fruit and vegetable intake and self-reported history of major cardiovascular events using population-based random samples. However, limitations should be considered while interpreting results. Firstly, a causal relationship could not be established due to the cross-sectional nature of the study. Further prospective studies are needed to explore the causal pathway between fruit and vegetable intake and major cardiovascular events in the Nepali population. Another limitation of this study is that both exposure and outcome variables were self-reported [7]. The information on duration of $\mathrm{MI} /$ stroke in the study is not known. Thus, we cannot establish that if the current trend on consumption of fruits and vegetables is due to recent cardiovascular events or culmination of behavior due to past cardiovascular events. The information on fruits and vegetables intake was based on self-reported 24-h and 1 week recalls, which may result in some recall bias; however, recall bias would have been minimized by using show cards and local languages for the type of fruits and vegetables and their units. Further, it was not possible to exclude potatoes and other tuberous roots from the total vegetable intake because both of them are strongly considered as vegetables in Nepal. Another important limitation of the study is that it did not take seasonal variation in the account. The availability and consumption of different types of fruits and vegetables in Nepal varies according to the season [11], which may underestimate or overestimate the intake of fruit and vegetable according to the season the data was collected.

\section{Conclusion}

The study reported that respondents currently smoking, with low BMI, having a history of cardiovascular events and belonging to other ethnicity except upper caste and janajati are significantly associated with lower consumption of fruit and vegetable intake. It was found that participants who consumed $<3$ servings of fruits and vegetables a day had higher odds of having a history of myocardial infarction or stroke in comparison to those who consumed $\geq 3$ servings of fruits and vegetables a day. This finding may be useful as a policy recommendation for those settings, where the current WHO recommendation of $\geq 5$ servings of fruits and vegetables is not possible. This association suggests that even patients with prior myocardial infarction or stroke do not modify nutritional intake according to guidelines. Additionally, the overall low intake of fruits and vegetables in Nepal is a risk factor for cardiovascular disease progression in Nepal. 


\section{Abbreviations}

AOR: Adjusted odds ratio; BMI: Body mass index; BP: Blood pressure; $\mathrm{Cl}$ : Confidence intervals; COBIN: Community based Management of noncommunicable diseases in Nepal; COR: Crude odds ratio; MET: Metabolic equivalent of task; WHO: World Health Organization; STEPS: STEPwise approach to surveillance tool

\section{Acknowledgements}

We would like to thank all the respondents who participated in this study for their valuable time.

\section{Authors' contributions}

SN wrote the first draft of the manuscript. The concept of this study was given by DN and SN. SN, AR and DN analyzed the data. AR, MHO, CSM, PK and DN contributed to manuscript revision. All the authors approved the final version of the manuscript.

\section{Funding}

No funding was received.

\section{Availability of data and materials}

The dataset used in this study is available upon reasonable request to COBIN study group principle investigator Dinesh Neupane (last author), who can be contacted through neupane.dinesh@gmail.com.

\section{Ethics approval and consent to participate}

The Nepal Health Research council approved the protocol for the original study (reference number 1065). All participants in the study provided written informed consent before the enrolment. The principle investigator of the COBIN study, Dinesh Neupane has full access to the COBIN dataset and the dataset used in this study was accessed upon reasonable request to him.

\section{Consent for publication}

Not applicable.

\section{Competing interests}

None.

\section{Author details}

${ }^{1}$ Nepal Development Society, Chitwan, Nepal. ${ }^{2}$ Department of Internal Medicine, Holbæk Hospital, Holbæk, Denmark. ${ }^{3}$ School of Health, Torrens University, Sydney, NSW, Australia. ${ }^{4}$ Research Unit for Global Health, Department of Public Health, Aarhus University, Aarhus, Denmark. ${ }^{5}$ Welch Center for Prevention, Epidemiology, and Clinical Research, Department of Epidemiology, Johns Hopkins University, Baltimore, MD, USA.

Received: 22 June 2020 Accepted: 20 September 2020

Published online: 24 September 2020

\section{References}

1. Liu RH. Health-promoting components of fruits and vegetables in the diet. Adv Nutr. 2013:4(3):384S-92S

2. Bvenura C, Sivakumar D. The role of wild fruits and vegetables in delivering a balanced and healthy diet. Food Res Int. 2017;99:15-30.

3. Alissa EM, Ferns GA. Dietary fruits and vegetables and cardiovascular diseases risk. Crit Rev Food Sci Nutr. 2017;57(9):1950-62.

4. World Health Organization. Diet, nutrition, and the prevention of chronic diseases: report of a joint WHO/FAO expert consultation, vol. 916. Geneva: World Health Organization; 2003.

5. World Health Organization. Global Strategy on Diet, Physical Activity and Health. Geneva: World Health Organization; 2003. Available at https://www. who.int/dietphysicalactivity/media/en/gsfs_fv.pdf.

6. Boeing $H$, Bechthold A, Bub A, Ellinger S, Haller D, Kroke A, LeschikBonnet E, Müller MJ, Oberritter $H$, Schulze M. Critical review: vegetables and fruit in the prevention of chronic diseases. Eur J Nutr. 2012:51(6):637-63.

7. Liu S, Manson JE, Lee I-M, Cole SR, Hennekens CH, Willett WC, Buring JE. Fruit and vegetable intake and risk of cardiovascular disease: the Women's health study. Am J Clin Nutr. 2000;72(4):922-8.

8. Dhungana RR, Thapa P, Devkota S, Banik PC, Gurung Y, Mumu SJ, Shayam A, Ali L. Prevalence of cardiovascular disease risk factors: a community- based cross-sectional study in a peri-urban community of Kathmandu, Nepal. Indian Heart J. 2018;70:S20-7.

9. Aryal KK, Mehata S, Neupane S, Vaidya A, Dhimal M, Dhakal P, Rana S, Bhusal CL, Lohani GR, Paulin FH. The burden and determinants of non communicable diseases risk factors in Nepal: findings from a nationwide STEPS survey. PLoS One. 2015;10(8):e0134834.

10. Neupane D, McLachlan CS, Christensen B, Karki A, Perry HB, Kallestrup P. Community-based intervention for blood pressure reduction in Nepal (COBIN trial): study protocol for a cluster-randomized controlled trial. Trials. 2016;17(1):292.

11. Pandey G, Basnet S, Pant B, Bhattarai K, Gyawali B, Tiwari A. An analysis of vegetables and fruits production scenario in Nepal. Asian Research Jounal of Agriculture. 2017;6(3):1-10.

12. World Health Organization. WHO STEPS surveillance manual: the WHO STEPwise approach to chronic disease risk factor surveillance. Geneva: World Health Organization; 2005.

13. Neupane D, Shrestha A, Mishra SR, Bloch J, Christensen B, McLachlan CS, Karki A, Kallestrup P. Awareness, prevalence, treatment, and control of hypertension in western Nepal. Am J Hypertens. 2017;30(9): 907-13.

14. Central Bureau of Statistics Nepal: National population and housing census 2011. National Report 2012.

15. Miller V, Mente A, Dehghan M, Rangarajan S, Zhang X, Swaminathan S, Dagenais G, Gupta R, Mohan V, Lear S. Fruit, vegetable, and legume intake, and cardiovascular disease and deaths in 18 countries (PURE): a prospective cohort study. Lancet. 2017;390(10107):2037-49.

16. World Health Organization: Obesity and overweight. 2005. http://www.who. int/dietphysicalactivity/publications/facts/obesity/en/.

17. Room R, Babor T, Rehm J. Alcohol and public health. Lancet. 2005;365(9458): 519-30.

18. James PA, Oparil S, Carter BL, Cushman WC, Dennison-Himmelfarb C, Handler J, Lackland DT, LeFevre ML, MacKenzie TD, Ogedegbe O. 2014 evidence-based guideline for the management of high blood pressure in adults: report from the panel members appointed to the eighth joint National Committee (JNC 8). Jama. 2014;311(5):507-20.

19. R Core Team. R: A language and environment for statistical computing. Vienna, Austria: R Foundation for Statistical Computing; 2020.

20. Joshipura KJ, Ascherio A, Manson JE, Stampfer MJ, Rimm EB, Speizer FE, Hennekens $\mathrm{CH}$, Spiegelman D, Willett WC. Fruit and vegetable intake in relation to risk of ischemic stroke. Jama. 1999;282(13):1233-9.

21. Johnsen SP. Intake of fruit and vegetables and risk of stroke: an overview. Curr Opin Clin Nutr Metab Care. 2004;7(6):665-70.

22. Wan EYF, Yu EYT, Chin WY, Fong DYT, Choi EPH, Lam CLK Association of Blood Pressure and Risk of cardiovascular and chronic kidney disease in Hong Kong hypertensive patients. Hypertension. 2019:74(2):331-40

23. Miller V, Yusuf S, Chow CK, Dehghan M, Corsi DJ, Lock K, Popkin B, Rangarajan S, Khatib R, Lear SA. Availability, affordability, and consumption of fruits and vegetables in 18 countries across income levels: findings from the prospective urban rural epidemiology (PURE) study. Lancet Glob Health 2016;4(10):e695-703

24. Gupta A, Mishra DK. Food consumption pattern in rural India: a regional perspective. J Econ Social Dev. 2014;9(1):1-16.

25. Wankhede G. Educational inequalities among scheduled castes in Maharashtra. Economic and Political Weekly. 2001;36(18):1553-8.

26. Wagle UR: Economic inequality in the 'democratic' Nepal: Dimensions and political implications. Western Michigan University Available at http:// homepages.wmich.edu/ uwagle/InegNepal.pdf. 2010.

27. Kanungsukkasem U, Ng N, Van Minh H, Razzaque A, Ashraf A, Juvekar S, Masud Ahmed S, Huu Bich T. Fruit and vegetable consumption in rural adults population in INDEPTH HDSS sites in Asia. Glob Health Action. 2009; 2(1):1988

28. Neupane D, McLachlan CS, Mishra SR, Olsen MH, Perry HB, Karki A, Kallestrup P. Effectiveness of a lifestyle intervention led by female community health volunteers versus usual care in blood pressure reduction (COBIN): an open-label, cluster-randomised trial. Lancet Glob Health. 2018; 6(1):e66-73.

29. Dhimal M, Bista B, Bhattarai S, Dixit LP, Hyder MKA, Agrawal N, Rani M, Jha AK. Noncommunicable disease risk factors: STEPS survey Nepal 2019. Kathmandu: Nepal Health Research Council; 2020. 
30. Government of Nepal, World Health Organization. Multisectoral Action Plan for the Prevention and Control of Non-communicable diseases (2014-2020). Kathmandu, Nepal: Government of Nepal and World Health Organization; 2010.

31. Nutrition Section, Child Health Division, Ministry of Health and Population (MOHP) [Nepal]. National Nutrition Policy and Strategy 2004. Kathmandu: Child Health Division, Ministry of Health and Population; 2004.

\section{Publisher's Note}

Springer Nature remains neutral with regard to jurisdictional claims in published maps and institutional affiliations.

Ready to submit your research? Choose BMC and benefit from:

- fast, convenient online submission

- thorough peer review by experienced researchers in your field

- rapid publication on acceptance

- support for research data, including large and complex data types

- gold Open Access which fosters wider collaboration and increased citations

- maximum visibility for your research: over $100 \mathrm{M}$ website views per year

At $\mathrm{BMC}$, research is always in progress.

Learn more biomedcentral.com/submissions 